\title{
Author Correction: MUC1-C regulates lineage plasticity driving progression to neuroendocrine prostate cancer
}

Yota Yasumizu, Hasan Rajabi, Caining Jin, Tsuyoshi Hata, Sean Pitroda, Mark D. Long (D, Masayuki Hagiwara, Wei Li, Qiang Hu (D), Song Liu, Nami Yamashita, Atsushi Fushimi, Ling Kui, Mehmet Samur, Masaaki Yamamoto, Yan Zhang, Ning Zhang, Deli Hong, Takahiro Maeda, Takeo Kosaka (1), Kwok K. Wong (1), Mototsugu Oya \& Donald Kufe (1)

Correction to: Nature Communications https://doi.org/10.1038/s41467-019-14219-6; published online 17 January 2020.

In the original version of this Article there was an error in Fig. 5. Figure $5 \mathrm{~g}$ was inadvertently duplicated from Fig. 5f. This has now been corrected in the PDF and HTML versions of the Article.

Published online: 24 February 2020

\footnotetext{
(c) Open Access This article is licensed under a Creative Commons Attribution 4.0 International License, which permits use, sharing, adaptation, distribution and reproduction in any medium or format, as long as you give appropriate credit to the original author(s) and the source, provide a link to the Creative Commons license, and indicate if changes were made. The images or other third party material in this article are included in the article's Creative Commons license, unless indicated otherwise in a credit line to the material. If material is not included in the article's Creative Commons license and your intended use is not permitted by statutory regulation or exceeds the permitted use, you will need to obtain permission directly from the copyright holder. To view a copy of this license, visit http://creativecommons.org/licenses/by/4.0/.
}

(C) The Author(s) 2020 